\title{
Role of polymorphs in inflammatory cartilage destruction in adjuvant arthritis of rats
}

\author{
W. MOHR, A. WILD, AND H. P. WOLF
}

From the Department of Pathology, University of Ulm, and the Rheumatism Section of Medical Research, E. Merck, Darmstadt

SUMMARY The inflammatory destruction of cartilage in rat adjuvant arthritis has been studied by histochemistry and autoradiography. Naphthol-AS-D-chloroacetate esterase has been used as a marker for polymorphs. The evidence presented here shows that polymorphs accumulate at the cartilage-pannus border and in areas of cartilage loss. These cells appear therefore to be of decisive importance for the destruction of cartilage. Proteoglycans were demonstrated by safranin-O staining: there is a loss of PG that is particularly prominent in zones where pannus had invaded cartilage. By means of ${ }^{35} \mathrm{~S}$ labelling of proteoglycans it was possible to show that pannus containing polymorphs can invade living cartilage.

The hyaline cartilage of joints, normally resistant to neoplastic invasion, ${ }^{2}$ can be completely destroyed by inflammatory disease. ${ }^{3}$ The mechanism of inflammatory cartilage destruction is not fully understood, although in rheumatoid arthritis it has been established that enzymes derived from pannus cells can destroy the cartilage matrix. ${ }^{45}$

Biochemical studies show that the enzymes of neutrophil granulocytes (polymorphs) are also capable of breaking down the components of cartilage matrix. ${ }^{67}$ Elastase, which can degrade proteoglycans as well as collagen, ${ }^{6-8}$ seems of particular importance. Nevertheless, the question of where and when the enzymes from polymorphs attack cartilage has not been clarified. Contrary to the findings of Mohr and Wessinghage, ${ }^{9}$ Mohr et al., ${ }^{10}$ and Menninger et al. ${ }^{11}$ most investigators believe that polymorphs are not found in rheumatoid arthritis pannus. ${ }^{46-15}$ However, it is accepted that the destructive infiltration of cartilage by polymorphs is characteristic of septic arthritis. ${ }^{16}$

These differing views may, of course, derive from analyses of rheumatoid synovia and cartilage obtained at different stages of the disease or patients subjected to entirely distinct therapeutic regimens.

Whether or not pannus from the articular recess $^{1718}$ invades living or only necrotic cartilage is also unknown. Investigations of adjuvant arthritis in the rat ${ }^{1920}$ and of rheumatoid arthritis in

Accepted for publication 1 May 1980

Correspondence to Professor W. Mohr, Abteilung Pathologie, Universität Ulm, 7900 Ulm, Eselsberg, West Germany. $\operatorname{man}^{10}$ suggest that pannus can invade cartilage in which chondrocytes remain viable, a view in accord with the role attributable to catabolin. ${ }^{21}$ However, there are still some who believe that destruction by pannus is confined to previously damaged or necrotic cartilage. $22-24$

The purpose of the present study was to answer the questions: (1) Can polymorphs play a role in the inflammatory destruction of cartilage? (2) What influence has inflammation on the characteristics of cartilage proteoglycans? (3) Can pannus invade living cartilage? It was decided to approach these questions with the rat adjuvant arthritis model, despite the limitation that this model is not precisely analogous with any known human disease.

\section{Material and methods}

Forty-eight 50-day-old AF/Han-EMD-SPF rats were used. Twenty-four animals received injections of $0.05 \mathrm{ml}$ complete Freund's adjuvant $(50 \mathrm{mg}$ suspension of Mycobacterium tuberculosis of strains $\mathrm{C}$, DT, and PN, in $50 \mathrm{ml}$ viscous paraffin, EMD Cat. No. 7160) intradermally into the sole of the right foot. Twenty-four untreated rats served as controls.

Seventeen and 31 days after administering the adjuvant both arthritic and nonarthritic rats (Fig. 1) were injected with radioactive sulphate intravenously ${ }^{35} \mathrm{~S}$-sodium sulphate in physiological saline, New England Nuclear Chemicals GmbH, Dreieichenhain). The activity administered amounted to 3 


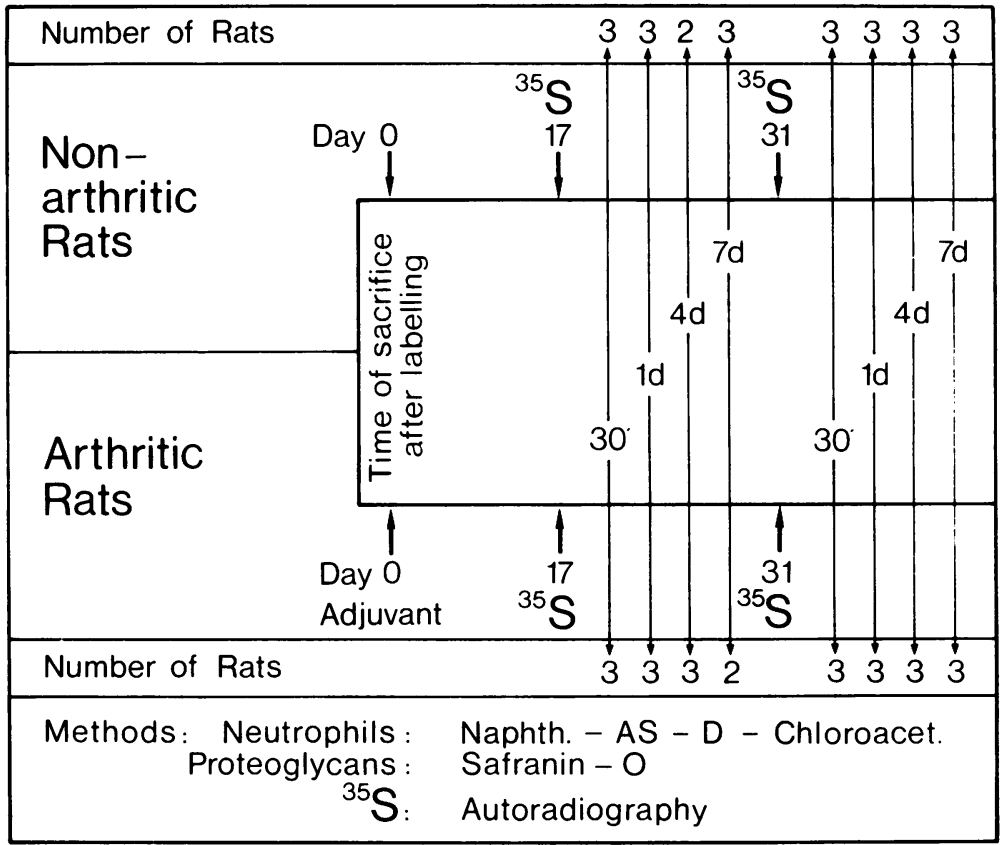

Fig. 1 Experimental design.

$\mu \mathrm{Ci} / \mathrm{g}$ body weight. During the course of the experiment 1 arthritic and 1 nonarthritic animal died.

$30 \mathrm{~min}$ and $1 \mathrm{~h}$ and 4 and 7 days after the injection of the ${ }^{35} \mathrm{~S} 3$ arthritic and 3 nonarthritic animals were perfused with buffered formalin while under an atmosphere of $\mathrm{CO}_{2}$ (Fig. 1). Both hind feet were separated and, after further fixation in neutral formalin, were decalcified in versene (Titriplex III). The feet were bisected. After paraffin embedding, $7 \mu \mathrm{m}$ sections were prepared.

Studies were always made of the tibiotarsal joint. Sections were stained with haematoxylineosin (HE) and reacted by the naphthol-AS-Dchloroacetate esterase (NADCE) method $^{25}$ to identify polymorphs. Proteoglycans (PG) were detected with safranin-O (S-O) ${ }^{26}$ For autoradiography sections were coated with Ilford $\mathrm{L}_{4}$ nuclear research emulsion and exposed in darkness for 11 days. After development, these sections were stained with HE.

\section{Results}

The results of the investigations of polymorph and of proteoglycan staining and of autoradiography recorded during the 17-24 and 31-38-day intervals (Fig. 1) were consolidated. No significant differences were found between the groups, although of course the destruction of cartilage was more advanced in the latter group.

\section{LOCALISATION OF}

NE UTROPHILIC GRANULOCYTES

There were normally no polymorphs in the articular capsule of nonarthritic animals.

Arthritis developed in all adjuvant injected animals. However, the extent of inflammation in animals killed after the 31st day had diminished, and in these animals there was advanced destruction of cartilage. The inflamed synovial and capsular tissue was heavily infiltrated by polymorphs.

When the cartilage surface was covered by pannus, it often contained many polymorphs. Polymorphs were seen to accumulate marginally on an intact cartilage surface (Fig. 2a); irregularities of the cartilage surface could also develop near these cell infiltrates. If in advanced cases there was destruction of cartilage, it was noted that narrow strips of cartilage were surrounded by polymorphs (Fig. 2b).

\section{SAFRANIN-O STAINABILITY}

Hyaline articular cartilage stained red in nonarthritic animals. However, minor differences were present in the stainability between the weakly stained superficial cartilage and the more intensively stained deeper cartilage.

In arthritic animals cartilage stainability depended on the extent of the inflammation. If there was only an inflammatory exudate in the joint space, then the cartilage stainability was comparable to that of control animals. If pannus had formed, cartilage 
adjacent to the pannus tissue stained less deeply. If pannus was invading cartilage, S-O stainability, particularly near the invading pannus, almost disappeared. Some chondrocytes remained in the vicinity, surrounded by a safraninophilic border; further away, cartilage matrix stained deeply (Fig. 2c). Small cartilage fragments completely surrounded by pannus usually showed little or no S-O reaction.

35 S LABELLING OF CARTILAGE

In nonarthritic animals silver grains were found, preferentially over chondrocytes $30 \mathrm{~min}$ after the injection of ${ }^{35} \mathrm{~S}$. A few silver grains were seen over adjacent matrix. Chondrocytes in the radial zone were more prominently labelled than those in the tangential cell layer. After 1 day the labelling over chondrocytes and intercellular matrix was more intense. There was a slight increase in the intensity of labelling on the 4th and 7th days; in particular, the labelling of the intercellular matrix was more intense.

In 17- and 31-day arthritic animals silver grains were preferentially localised over chondrocytes, but

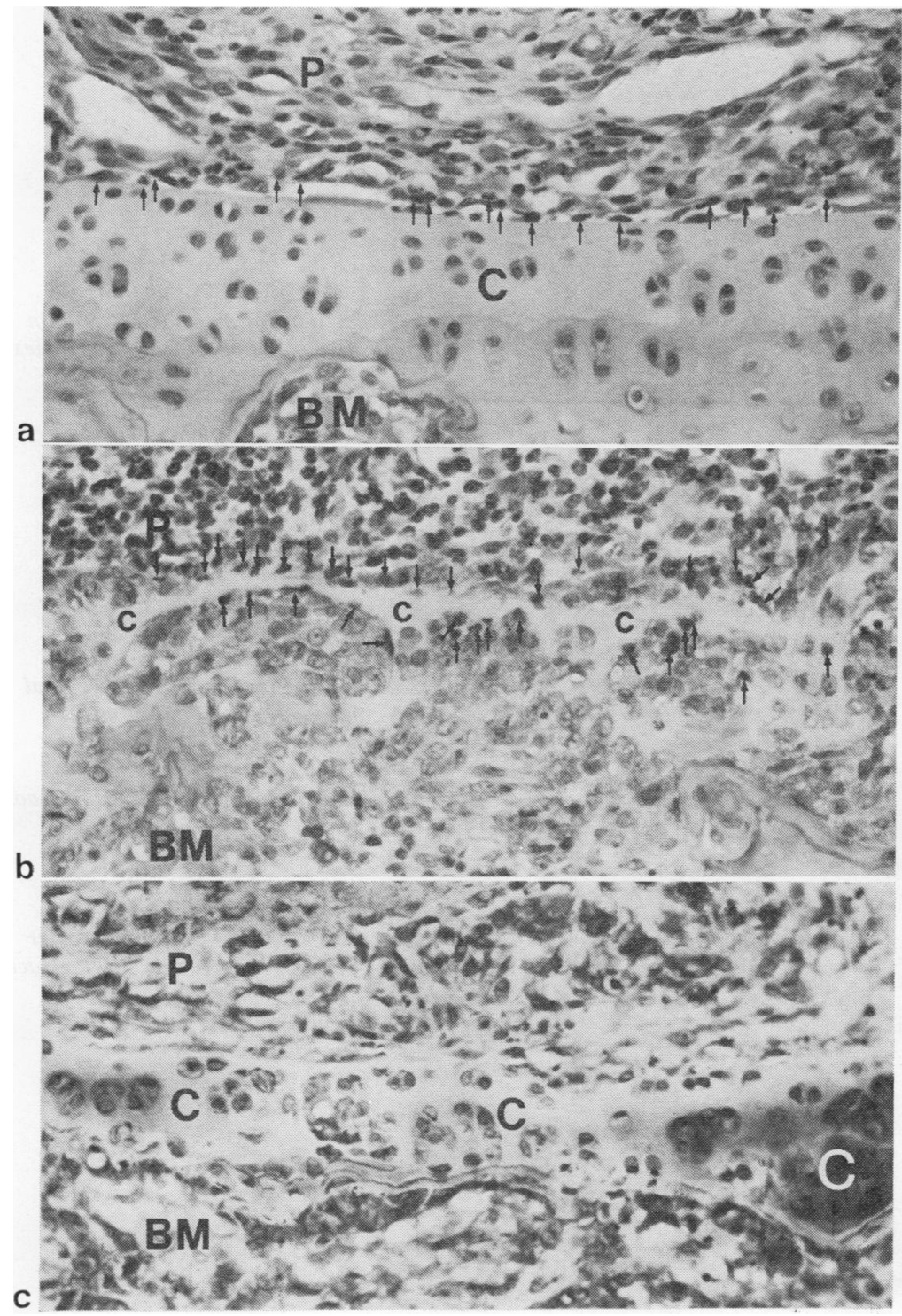

Fig. 2 (a): Pannus (P) at cartilage surface. In area immediately bordering the smooth cartilage surface (C) accumulations of polymorphs (arrows). (BM = bone marrow annus). (NADCE, × 267). (b): Narrow strip of remaining cartilage $(\mathrm{C})$ surrounded by border of polymorphs (arrows) which invade the cartilage from superficial pannus $(\mathrm{P})$ and from bone marrow pannus (BM). (NADCE, $\times$ 267). (c): Almost complete loss of $\mathrm{S}-\mathrm{O}$ stainability in cartilage severely destroyed by pannus (black C). Retained $\mathrm{S}-\mathrm{O}$ stainability of cartilage border not invaded (white $\mathrm{C})(\mathrm{P}=$ surface pannus, $\mathrm{BM}=$ bone marrow pannus $)$. (S-O, $\times 267)$. 
in smaller amounts over the intercellular matrix $30 \mathrm{~min}$ after injecting ${ }^{35} \mathrm{~S}$. Silver grains were present over cartilage with (Fig. 3a) and without pannus. In several joints cartilage covered or invaded by pannus (Fig. 3b) was less intensely labelled. In areas where polymorphs had penetrated, the cartilage matrix labelling was usually reduced. Nevertheless it was evident that there were still silver grains over chondrocytes when polymorphs lay nearby (Fig. 3c).

Labelling of chondrocytes and of the intercellular matrix was intense in arthritic animals after 1 day. Pannus-covered cartilage showed lower radioactivity in several animals, but radioactivity was still present even when the cartilage was surrounded or invaded by pannus.

After 4 days labelling was intense over the chondrocytes and matrix in arthritic animals. The labelling of pannus-covered cartilage was usually of low intensity; labelling was also slight when cartilage was invaded by pannus.

The findings at day 7 after labelling with ${ }^{35} \mathrm{~S}$ were comparable to those on the 4th day. There was intense labelling not only of chondrocytes but also of intercellular substance. Pannus-covered cartilage

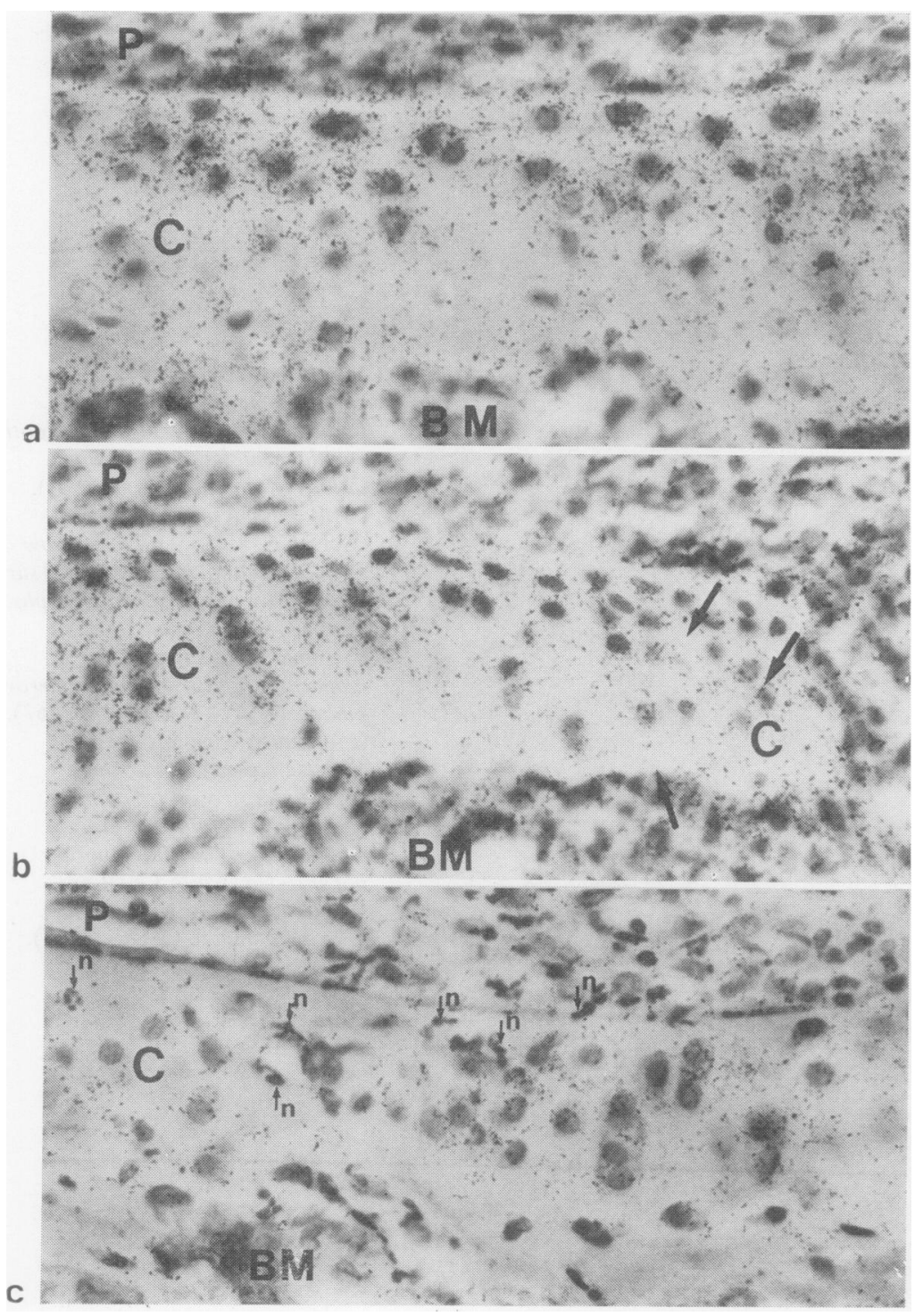

Fig. 3 (a): ${ }^{35} \mathrm{SO}_{4}$ labelling of cartilage of arthritic rat 30 min after injection of isotope. Highest degree of labelling is over chondrocytes; only few silver grains above intercellular matrix ( $\mathrm{C}=$ cartilage, $\mathrm{P}=$ surface pannus, $\mathrm{BM}=$ bone marrow pannus). (Autoradiograph, $H$ and $E, \times 423) .(\mathrm{b}):{ }^{35} \mathrm{SO}_{4}$ labelling of cartilage of arthritic rat 30 min after injection of isotope. Slight difference between cartilage invaded by pannus (arrows) and adjacent area showing no invasion $(\mathrm{C}=$ cartilage, $\mathbf{P}=$ surface pannus, $\mathrm{BM}=$ bone marrow pannus). (Autoradiograph, $H$ and $E, \times 423)$. (c): Slight ${ }^{35} \mathrm{SO}_{4}$ labelling over cartilage invaded by pannus with many invading polymorphs $(\mathrm{n})$ (arthritic rat-30 minutes after $\left.{ }^{35} \mathrm{~S}\right)(\mathrm{C}=$ cartilage, $\mathrm{P}=$ surface pannus, $\mathrm{BM}=$ bone marrow pannus). (Autoradiograph, $H$ and $E, \times 423)$. 
showed silver grains over chondrocytes and matrix. However, the number of silver grains in cartilaginous areas covered by pannus was decreased.

\section{Discussion}

In rat adjuvant arthritis those synovial joints that are principally affected are destroyed within a few weeks. The process terminates in fibrous and in bony ankylosis. In rheumatoid arthritis in man many years may elapse before the synovial joints are destroyed to a similar extent. Despite this significant difference, some of the morphological events in cartilage destruction may be comparable in both diseases. The animal model therefore may be used to examine 3 questions regarding cartilage destruction.

Two principal arguments have been advanced against the role of polymorphs in cartilage destruction in nonbacterial arthritis. First, the granulocyte proteases of synovial fluid are inactivated by inhibitors ${ }^{27}$; secondly, no granulocytes are said to exist in pannus near the injured cartilage. ${ }^{412-15} 28$

In earlier studies of adjuvant arthritis the presence of polymorphs in the areas of cartilage destruction was confirmed. ${ }^{19} 29$ The present investigations show that many polymorphs are present in the pannus: they accumulate at the pannus-cartilage border but are also present in cartilage resorption lacunae and can surround islands of disrupted cartilage. The capacity of granulocytic enzymes to destroy cartilage matrix has been investigated primarily in human leucocytes, ${ }^{6-8}$ 30-32 but Anderson ${ }^{33}$ detected collagenase in rat polymorphs. It may be concluded that these cells release enzymes directly at the cartilage-pannus border, leading to cartilage destruction, confirming opinions regarding the pathogenesis of rheumatoid ${ }^{9-11}$ and infectious arthritis. ${ }^{34}$ Neutrophilic granulocytes can therefore be said to be of significance in destroying cartilage in the acute stages of the human and animal disease; however, this does not exclude the participation in cartilage destruction of mononuclear pannus cells causing a slowly progressive cartilage loss.

Safranin staining can reveal the proteoglycan content of cartilage ${ }^{26}$ in man and the rat.

Human arthritis leads to an early loss of PG..$^{35-38}$ In rat adjuvant arthritis there is only a slight decrease in S-O stainability. The greatest loss occurs in areas where invasive pannus penetrates cartilage. It can therefore be concluded that not only the loss of PG but also the destruction of cartilage is most pronounced where pannus has come into direct contact with cartilage. ${ }^{39}$ Both enzymes from the pannus cells ${ }^{4}$ and those from polymorphs $^{40}$ may be able to degrade PG. Since elastase can be traced by the NADCE reaction ${ }^{11}$ it can be assumed that this enzyme is present in the polymorphs of the rat and that it can be effective in degrading PG of cartilage in rat adjuvant arthritis. Notwithstanding Dingle's ${ }^{21}$ views, chondrocyte enzymes appear less significant in PG destruction: in areas remote from pannus, where the S-O stainability of the matrix is reduced, the chondrocytes are surrounded by zones of safraninophilic material. This finding supports the view of Panagides et al, ${ }^{\mathbf{4 1}}$ who concluded that chondrocyte enzymes have no significance in cartilage destruction.

Pannus is thought to grow into previously damaged cartilage. ${ }^{22-24}$ The ability of the chondrocytes to incorporate ${ }^{35} \mathrm{~S}$ and release labelled GAG into the intercellular substance is an essential function of the living cells. ${ }^{42-44}$ Because pannus penetrates cartilage labelled with ${ }^{35} \mathrm{~S}$, it can be concluded that living cartilage is destroyed.

Observations made in the first $24 \mathrm{~h}$ after ${ }^{35} \mathrm{~S}$ labelling indicate the viability of chondrocytes. However, autoradiographic findings 4 and 7 days after ${ }^{35} \mathrm{~S}$ administration can be interpreted in alternative ways. Because there is reduced labelling near invading pannus it can be assumed that enzymes from the pannus cells or granulocytes intensify PG destruction, supporting the results of tests of cartilage with S-O staining and corroborating the view that there is lysis of PG in the immediate neighbourhood of pannus. This indicates that loss of PG is not the cause but rather the result of pannus destruction. On the other hand the possibility that a reduced incorporation of ${ }^{35} \mathrm{~S}$ occurs in cartilage surrounded by pannus must also be taken into consideration.

It therefore appears, first, that neutrophilic granulocytes are significant cellular constituents in the inflammatory cartilage destruction of rat adjuvant arthritis; secondly, that enzymes of the invading pannus are particularly capable of destroying proteoglycans in the invaded zones; and, thirdly, that pannus can destroy living cartilage.

The investigations were supported by a grant of the Deutsche Forschungsgemeinschaft (Mo 183/6).

The capable technical help of Mrs R. Endres-Klein and Miss B. Blell is gratefully acknowledged.

\section{References}

1 Dontenwill W, Chevalier H J, Reckzeh G. Growth of carcinomas in the region of cartilage. $J$ Natl Cancer Inst $1973 ; 50: 291-3$.

2 Mohr W. Zur Pathogenese der Gelenkknorpelzerstörung bei der chronischen Polyarthritis. Aktuel Rheumatol 1977; 2: 119-31.

3 Hunter W. Of the structure and diseases of articulating cartilage. Philos Trans $R$ Soc Lond 1743; 42: 514-22. 
4 Harris E D, Faulkner C S, Brown F E. Collagenolytic systems in rheumatoid arthritis. Clin Orthop 1975; 110: 303-16.

5 Woolley D E, Glanville R W, Crossley M J, Evanson J M. Purification of rheumatoid synovial collagenase and its action on soluble and insoluble collagen. Eur J Biochem 1975; 54: 611-22.

6 Barrett A J. Capacity of leucocyte elastase and cathepsin $\mathbf{G}$ to degrade mature collagen fibers. In: Havemann $\mathrm{K}$, Janoff A, eds. Neutral proteases of human polymorphonuclear leukocytes. Baltimore-Munich: Urban and Schwarzenberg, 1978: 385-9.

7 Ohlsson K. Purification and properties of granulocyte collagenase and elastase. In: Havemann K, Janoff A, eds. Neutral proteases of human polymorphonuclear leukocytes. Baltimore-Munich: Urban and Schwarzenberg, 1978: 89-101.

8 Starkey P M, Barrett A J, Burleigh M C. The degradation of articular collagen by neutrophilic proteinases. Biochim Biophys Acta 1977; 483: 386-97.

9 Mohr W, Wessinghage D. The relationship between polymorphonuclear granulocytes and cartilage destruction in rheumatoid arthritis. $Z$ Rheumatol $1978 ; 37: 81-6$.

10 Mohr W, Menninger H, Putzier R. Morphologische Hinweise für die Beteiligung neutrophiler Granulozyten bei der rheumatischen Knorpeldestruktion. Bull Schweiz Akad Med Wiss 1979; 35: 443-51.

11 Menninger H, Putzier R, Mohr W, Hering B, Mierau $H$ D. Role of granulocyte elastase in rheumatoid arthritis: effect on mechanical behavior of cartilage and identification at the cartilage pannus junction. 30 . Mosbacher Kolloquium der Gesellschaft für Biologische Chemie. Biological functions of proteinases. BerlinHeidelberg-New York: Springer, 1979: 196-206.

12 Harris E D, Dibona D R, Krane S M. Mechanisms of destruction of articular structures in rheumatoid arthritis. Excerpta Medica International Congress Series 1970; 229: 243-53.

13 Krane S M. Collagenase production by synovial tissues. Ann N Y Acad Sci 1975; 256: 289-303.

14 Woolley D E, Crossley M J, Evanson J M. Collagenase at sites of cartilage erosion in the rheumatic joint. Arthritis Rheum 1977; 20: 1231-9.

15 Muirden K D, Rogers K. Electron microscopy and synovial pathology. Aust NZ J Med 1978; 8 Suppl 1: $20-4$.

16 Hatschek $O$. Über das mikroskopische Bild der akuten. metastatischpyämischen Gelenkseiterung. Beitr Pathol 1929; 82: 606-10.

17 Mohr W, Wild Á. The proliferation of chondrocytes and pannus in adjuvant arthritis. Virchows Archiv (Cell Pathol) 1977; 25: 1-16.

18 Mohr W, Wild A. Autoradiographische Untersuchungen zur Pannusentwicklung bei der Adjuvansarthritis der Ratte. Wien Klin Wochenschr 1977; 89: 756-65.

19 Mohr W, Wild A, Wolf H P. Incorporation of ${ }^{3} \mathrm{H}$ proline into hyaline articular cartilage. Virchows Archiv (Cell Pathol) 1978 ; 28 : 1-12.

20 Mohr W, Wild A. ${ }^{3}$ H-Prolin-Inkorporation in den Gelenkknorpel. Verh Dtsch Ges Rheumatol (in press).

21 Dingle J T. Recent studies on the control of joint damage: the contribution of the Strangeways Research Laboratory. Ann Rheum Dis 1979; 38: 201-14.

22 Kulka J P. The pathogenesis of rheumatoid arthritis. J Chronic Dis 1959; 10: 388-402.

23 Cooper N S. Pathology of rheumatoid arthritis. Med Clin North Am 1968; 52: 607-21.
24 Chaplin D M. The pattern of bone and cartilage damage in the rheumatoid knee. J Bone Joint Surg 1971; 53B: 711-7.

25 Leder L D. Der Blutmonozyt. Berlin-Heidelberg-New York: Springer, 1967.

26 Rosenberg L. Chemical basis for the histological use of safranin $\mathrm{O}$ in the study of articular cartilage. J Bone Joint Surg 1971; 53A : 69-82.

27 Ohlsson K. Alpha 1-antitrypsin and alpha 2-macroglobulin interaction with human neutrophilic collagenase and elastase. Ann NY Acad Sci 1975; 256: 409-19.

28 Barrett A J. The possible role of neutrophil proteinase in damage to articular cartilage. Agents Actions 1978; 8: 11-8.

29 Mohr W, Wild A. Der Ablauf der Adjuvanskrankheit bei Ratten des Stammes AF/Han-EMD-SPF. $Z$ Rheumatol 1976; 35: 77-90.

30 Oronsky A L, Perper R J, Schroder H C. Phagocytic release and activation of human leukocyte procollagenase. Nature 1973; 246: 417-9.

31 Keiser H, Greenwald R A, Feinstein G, Janoff A. Degradation of cartilage proteoglycans by human leukocyte granule neutral proteases - a model of joint injury. J Clin Invest 1976; 57: 625-32.

32 Steven F S, Torre-Blanco A, Hunter J A A. A neutral protease in rheumatoid synovial fluid capable of attacking the telopeptide regions of polymeric collagen fibrils. Biochim Biophys Acta 1975; 405: 188-200.

33 Anderson A J. Enzyme system in rat leucocyte granules which degrades insoluble collagen. Ann Rheum Dis 1971; 30: 299-302.

34 Mohr W, Wessinghage D. Knorpelzerstörung im bakteriell superinfizierten rheumatischen Gelenk. Aktuel Rheumatol 1980; 5: 145-56.

35 Janis R, Hamerman D. Articular cartilage changes in early rheumatoid arthritis. Bull Hosp Joint Dis 1969; 30: 136-52.

36 Aufdermaur M. In: Arthrosis-Arthritis-degenerativer Rheumatismus. Verh Dtsch Ges Orthop Traumatol, 1970; 57:9-12.

37 Gardner D L. The pathology of rheumatoid arthritis. London: Arnold, 1972.

38 Inderau H J, Schramm G. Untersuchungen zur Beurteilung des Gelenkknorpels bei der c.P. Beitr Orthop 1972; 19: 568-72.

39 Mohr W, Hersener J, Wild A, Paulini K. Untersuchungen zum Knorpelabbau bei der Adjuvanskrankheit der Ratte. $Z$ Rheumatol 1975; 34: 234-42.

40 Janoff A, Feinstein G, Malemud C J, Elias J M. Degradation of cartilage proteoglycans by human leukocyte granule neutral protease-a model for joint injury. $J$ Clin Invest 1976; 57: 615-24.

41 Panagides J, Landes M J, Sloboda A E. Breakdown of articular cartilage proteoglycans by arthritic synovium in vitro. Fed Proc 1978; 37: 642 (abstract).

42 Depalma A F, Tsaltas T T, Mauler G G. Viability of osteochondral grafts as determined by uptake of $\mathrm{S}^{35}$. J Bone Joint Surg 1963; 45A : 1565-78.

43 Pelc S R, Glücksmann A. Sulphate metabolism in the cartilage of the trachea, pinna and xiphoid process of the adult mouse as indicated by autoradiography. Exp Cell Res $1955 ; 8$ : 336-44.

44 Collins D H, Meachim G. Sulphate $\left({ }^{35} \mathrm{SO}_{4}\right)$ fixation by human articular cartilage compared in the knee and shoulder joints. Ann Rheum Dis 1961 ; 20 : 117-22. 